\title{
Genetic diversity in the parthenogenetic reproducing tardigrade Echiniscus testudo (Heterotardigrada: Echiniscoidea)
}

\author{
Aslak JøRGENSEN, ${ }^{1 *}$ Søren FAURBY, ${ }^{2}$ Dennis KROG PERSSON,,${ }^{1,3}$ Kenneth AGERLIN HALBERG, ${ }^{3}$ \\ Reinhardt MØBJERG KRISTENSEN, ${ }^{1}$ Nadja MØBJERG ${ }^{3}$
}

${ }^{1}$ Laboratory of Molecular Systematics, The Natural History Museum of Denmark, University of Copenhagen, Sølvgade 83, DK-1807 Copenhagen; ${ }^{2}$ Department of Bioscience, Aarhus University, Nordre Ringgade 1, 8000 Aarhus; ${ }^{3}$ Department of Biology, August Krogh Centre, University of Copenhagen, Nørregade 10, DK-1017 Copenhagen, Denmark

*Corresponding author: aslak@snm.ku.dk

\begin{abstract}
Little is known about the genetic structure of microscopic animals from mosses and lichens. A few studies have investigated the geographic variation in tardigrades from mosses, but so far no study has investigated the intra-population or local clonal lineage variation. Echiniscus testudo (Echiniscoidea: Echiniscidae) belongs to a large cosmopolitan genus of terrestrial tardigrades comprising more than 150 species. It is a common tardigrade in mosses in the temperate part of the Northern hemisphere, and is highly tolerant of desiccation and freezing. In a previous study, we reported a maximum of $1.28 \%$ sequence variation (uncorrected $\mathrm{p}$-distance) in cytochrome c oxidase subunit I (COI) haplotypes between clonal lineages covering a large geographical area. However, in this previous study we used pooled specimens to constitute a sample, and the genetic diversity from single specimens within a locality therefore remains unknown. Accordingly, the present study investigates the COI sequence variation and haplotype diversity between single specimens of E. testudo collected at three Danish localities, separated by $80 \mathrm{~m}$ and $186 \mathrm{~km}$. A total of 10 COI haplotypes were found in the present study (Et2, Et3, Et9, Et12-Et18); only three of these were previously reported (Et2, Et 3 and Et9). The uncorrected COI sequence diversity ranged between 0-2.07\%, with haplotype Et18 having the highest genetic difference. The second most variable haplotypes (Et14, Et15, and Et17) all showed a maximum diversity of 1.19\% compared to the other haplotypes. No general pattern of haplotype distribution was evident. Our data suggest that E. testudo has dispersed across the Baltic sea as haplotypes Et 3 , Et 13 and Et 14 are present at all three localities. The most likely dispersal mode is passive wind dispersal in the cryptobiotic tun stage. The current study emphasises that numerous sequences from single specimens are needed to describe the genetic diversity within single moss cushions.
\end{abstract}

Key words: Tardigrada, Echiniscidae, sequence variation, COI, minimum spanning network.

\section{INTRODUCTION}

Genetic variation in microscopic animals living in large water bodies has received some attention with a large amount of information available on various species, especially of the rotifer genus Brachionus (Gómez et al., 2002; Suatoni et al., 2006; Gómez et al., 2007) and the crustacean genus Daphnia (Straughan and Lehman, 2000; De Gelas and De Meester, 2005; Ishida and Taylor, 2007). In contrast, the genetic structure of microscopic animals from mosses and lichens is almost unknown. A few studies have looked at geographic variation in tardigrades from mosses on a larger geographical scale (Jørgensen et al., 2007; Faurby et al., 2008), but so far, no study has looked into the intrapopulation or local clonal lineage variation.

Tardigrades are microscopic metazoans inhabiting various terrestrial, limnic and marine substrates. The presence of a film of free water is a prerequisite for active tardigrades. Many species of tardigrades, primarily those living in mosses and lichens, are famous for their ability to enter cryptobiosis, a form of latent life, during desiccation (Wright et al., 1992; Møbjerg et al., 2011).

Within echiniscoidean tardigrades, sequences from the mitochondrial gene cytochrome c oxidase subunit I (COI) have previously been used to investigate: i) the genetic diversity in Echiniscus testudo (Doyère, 1840) over a large geographic area (Jørgensen et al., 2007); ii) the phylogeography of Echiniscoides (Faurby et al., 2011, 2012); iii) the taxonomic status, ecological patterns and phylogeography of various Echiniscus C:A.S. Schultze, 1840 species (Guil and Giribet, 2009); and iv) the phylogeny of Echiniscidae (Jørgensen et al., 2011). Our test species, E. testudo (Echiniscoidea: Echiniscidae), belongs to a large cosmopolitan genus of terrestrial tardigrades, comprising more than 150 species (Guidetti and Bertolani, 2005). It is a common tardigrade in mosses in the temperate part of the Northern hemisphere, and it is highly tolerant of desiccation and freezing (R.M. Kristensen, personal observation). The genus was once thought to be entirely parthenogenetic (Kristensen, 1987), but later studies have found males to be common in some non-European species (Dastych and Kristensen, 1995; Miller et al., 1999). Mitchell and Romano (2007) and Guil and Giribet (2009) reported the relatively low occurrence of 7 and 2.6\% males in Echiniscus manccii Ramazzotti, 1956 (North America) and Echiniscus 
blumi-canadensis complex (Spain), respectively. Echiniscus testudo is reported from several European countries (McInnes, 1994) and males have never been reported, so predominantly parthenogenetic reproduction is therefore likely (Jørgensen et al., 2007).

Passive wind dispersal of tardigrades has been demonstrated by Janiec (1996), and long range dispersal was suggested based on molecular data by Jørgensen et al. (2007). Parthenogenetic reproduction combined with long term survival in cryptobiotic stages gives E. testudo a strong potential for colonising new habitats.

Here, we investigate the COI sequence variation and haplotype diversity based on single specimens of the tardigrade E. testudo at three Danish localities and separated by the Baltic sea. The specific objectives are i) to investigate the genetic diversity of COI within different geographic scales, and ii) to compare the new results with the haplotypes reported in Jørgensen et al. (2007).

\section{METHODS}

\section{Specimen sampling}

Tardigrades were collected from the roof of a single house at each of three Danish localities (Fig. 1). One locality was on the island of Bornholm (L11; 55 $04^{\prime} 05.65^{\prime \prime} \mathrm{N}$, $\left.15^{\circ} 01^{\prime} 19.75^{\prime \prime} \mathrm{E}\right)$ in the Baltic sea, whereas the two others were situated close to each other, within $80 \mathrm{~m}$, on northern Zeeland (T101; 55 $56^{\prime} 36.68^{\prime \prime} \mathrm{N}, 12^{\circ} 29^{\prime} 55.85^{\prime \prime} \mathrm{E}$ and T315; $55^{\circ} 56^{\prime} 36.53^{\prime \prime} \mathrm{N}, 12^{\circ} 30^{\prime} 00.90^{\prime \prime} \mathrm{E}$ ). The locality on Bornholm is approximately $186 \mathrm{~km}$ from the two latter localities (distance measured using Google Earth). At all three localities, we took a number of moss samples from the roof of a single house (16 in both L11 and T315 and 20 in T101). The samples were taken in pairs except for samples 15-16 from L11 and 9-12 from T101. The moss cushions did not form a continuous blanket, but were patchily distributed. The paired samples were taken maximally $0.5 \mathrm{~m}$ apart, and constituted a single distinct moss cushion each. Samples were washed through a fine sieve $(62 \mu \mathrm{m})$, and tardigrades were identified under a dissecting microscope. Echiniscus testudo is the only echiniscid present at the localities, and it is easily recognized by its iridescent cuticle and (dark)-orange color. A total of 52 moss samples were collected; however, COI sequences were only recovered from 44 moss samples due to the absence of $E$. testudo in some mosses (6 samples) and failed polymerase chain reaction (PCR) amplification and sequencing ( 2 samples). Of the 44 moss samples from which $\mathrm{COI}$ sequences were obtained, 13 moss samples originated from L11, 17 moss samples from T101 and 14 moss samples from T315, respectively.

\section{Molecular work}

Single live specimens were transferred into $2 \mu \mathrm{L}$ of sodium-tris-EDTA (STE)-buffer on a glass slide, and care- fully shredded with sharp needles prior to transfer into an Eppendorf tube. The DNA extractions were carried out using the STE-buffer DNA extraction method (Maniatis et al., 1982).

A fragment of the cytochrome $\mathrm{c}$ oxidase subunit I gene (COI) was amplified using the primers from Folmer et al. [1994; LCO1490 (forw.)] and Schwendinger and Giribet [2005; HCOout (rev.)]. Polymerase chain reaction amplifications were conducted according to Jørgensen et al. (2007). The PCR products were loaded on a $2 \%$ agarose gel, and successful amplifications were sequenced with an ABI310 automated sequencer (Life Technologies Ltd, Paisley, UK) following the set up in Jørgensen et al. (2007). Forward and reverse sequences were compared and edited using ChromasPro (Technelysium, Australia). The sequences have been deposited in GenBank (Acc. no. KC544274 - KC544458).

\section{Data analyses}

Sequence alignment was conducted using ClustalX2 (Larkin et al., 2007); no length polymorphism was found. All sequences were translated to amino acids using the standard invertebrate mitochondrial code in MEGA4 (Tamura et al., 2007) to check for stop-codons, which would indicate the presence of pseudo-genes. None of these were found, and the vast majority of mutations were synonymous. It was therefore assumed that all sequences represent functional mitochondrial sequences. MEGA4 was also used to calculate the uncorrected and Kimura 2parameter genetic diversity of the nucleotide sequences, and to compute Tajima's Neutrality Test. Haplotype diversity, mean number of pairwise differences between haplotypes, and nucleotide diversity were calculated using Arlequin v3.5.1.3 (Excoffier et al., 2005). Isolation by distance (IBD) was tested by Mantel tests in Isolation By Distance Web Service v3.23 (Jensen et al., 2005).

Minimum spanning network of the COI haplotypes was obtained using TCSv1.21 to visualise the distribution of genetic variation (Clement et al., 2000).

A data matrix consisting of COI haplotypes from $E$. testudo and Echiniscus sp. (EF620367.1; formerly known as E. cf. testudo haplotype Et1) was used to infer a phylogenetic tree using Bayesian inference (MrBayes 3.2.1; Ronquist and Huesenbeck, 2003). MrModeltest 2.2 (Nylander, 2004) was used to calculate the substitution model $(\mathrm{HKY}+\mathrm{G})$ that fitted the data best using the Akaike information criterion. The analysis was run with 10 million generations and the summarised sample parameter values were used to discard sampled trees prior to the point of convergence as burnin (2000 trees).

\section{RESULTS}

We succeeded in amplifying a 588 bp fragment of COI from 185 specimens, with an $\mathrm{A} / \mathrm{T}$ rich nucleotide compo- 
T315

\begin{tabular}{|c|c|}
\hline $\begin{array}{l}\text { - } 9 \text { Et13, Et14 } \\
\text { - } 10 \text { Et3, Et12, Et18 }\end{array}$ & $\begin{array}{l}\text { Et3, Et12, Et14 8• } \\
\text { Et3, Et12, Et14 } 7 \bullet\end{array}$ \\
\hline $\begin{array}{l}\text { - } 11 \mathrm{Et}, \mathrm{Et} 12 \\
\text { - } 12 \mathrm{Et} 3, \mathrm{Et} 12\end{array}$ & $\begin{array}{r}\mathrm{Et} 3, \mathrm{Et} 126 \\
50\end{array}$ \\
\hline $\begin{array}{l}\text { - 13Et3, Et9 } \\
\text { - 14Et3 }\end{array}$ & $\begin{array}{r}40 \\
\text { Et3 } 3 \bullet\end{array}$ \\
\hline $\begin{array}{l}\text { - } 15 \mathrm{Et3} \\
\text { - } 16 \mathrm{Et} 3\end{array}$ & $\begin{array}{r}\text { Et3, Et9 } 2 \bullet \\
\text { Et3 } 1 \bullet\end{array}$ \\
\hline
\end{tabular}
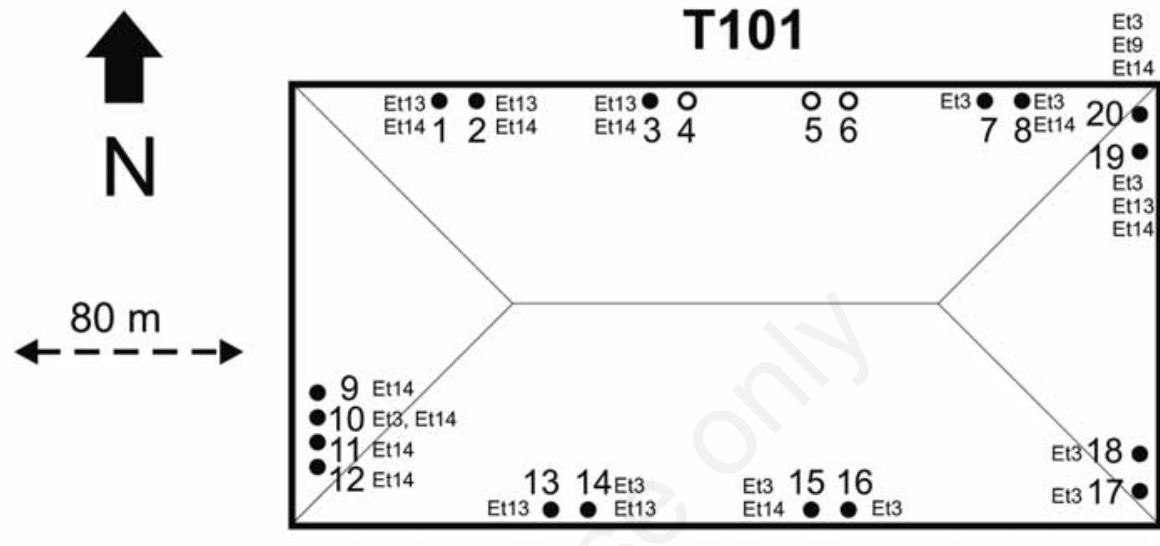

4

$186 \mathrm{~km} \mathrm{I}$

I

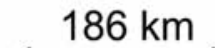

L11
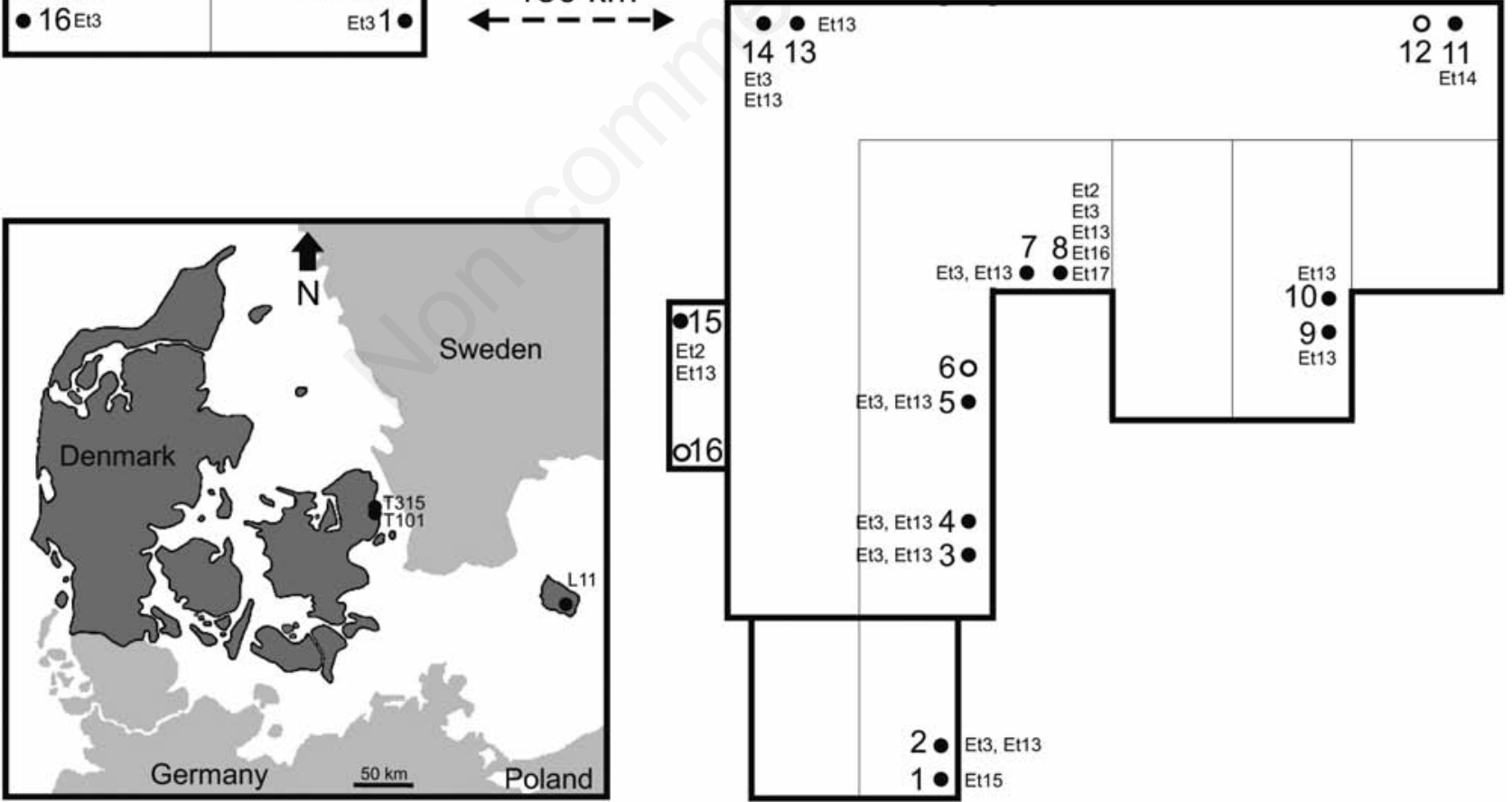

Fig. 1. Localities and sampling sites. The inserted locality map (bottom left) shows the Danish sampling localities and neighbouring countries Sweden, Germany and Poland. The three localities (roofs) are viewed from above as rectangles with bold lines. The actual sampling sites are indicated with circles. Open circles indicate the absence of Echiniscus testudo or failed amplification of cytochrome c oxidase subunit I; black circles indicate the presence of Echiniscus testudo. The locality L11 on the island of Bornholm in the Baltic sea is approximately $186 \mathrm{~km}$ from the two localities T101 and T315 at Nivå, Zeeland. 
sition: A (24.0\%), C (14.2\%), G (15.7\%) and T (46.1\%). Tajima's Neutrality Test indicated neutral evolution of the sequences. The number of successful amplifications per moss sample ranged from one to eight (Fig. 2A), distributed with 53, 72 and 60 specimens from L11, T101 and T315, respectively (Tab. 1).

The uncorrected COI sequence variation ( $p$-distance) ranged between $0-2.07 \%$, with haplotype Et1 8 from T315 accounting for the highest value $(2.07 \%)$. The second most variable haplotypes (Et14, Et15 and Et17) showed a maximum diversity of $1.19 \%$ compared to the other sequences. The genetic diversity was not larger between localities $186 \mathrm{~km}$ apart than between localities $80 \mathrm{~m}$ apart. Even with the removal of the most divergent haplotype (Et18), the maximum uncorrected $p$-distance value was $1.19 \%$ between T101 and T315 (several haplotypes). Based on Mantel tests using the fixation index $\left(\mathrm{F}_{\mathrm{ST}}\right)$ values there was no evidence of isolation by distance of the haplotypes between the three localities (Tab. 2).

Ten COI haplotypes were found in total, with only three of the eleven haplotypes (Et2, Et3 and Et9) reported in Jørgensen et al. (2007) being recollected. The locality L11 had seven haplotypes, while T101 and T315 had four and six, respectively. The number of haplotypes per moss sample ranged from one to five (Fig. 2B), with a mean of 1.77. The haplotype diversity was 0.70 , the mean number of pairwise differences between haplotypes was 2.01, and the nucleotide diversity (average over haplotypes) was $0.34 \%$. The haplotype Et2, originally described from France and Germany, is present at L11. The haplotype Et3, originally described from L11 in 2007, was recollected at L11, and in the present collection it was also found at T101 and T315. Et3 was the most abundant haplotype present in 85 specimens. The haplotype Et9 originally described from L11 was not recollected at this locality, but was present in one and two specimens at T101 and T315, respectively. Four out of the seven new haplotypes reported in the present study were singletons (only collected once). From the nonsingleton new haplotypes, one (Et12) was present only at T315, and two (Et13 and Et14) were shared among all three localities (Tab. 1).

Three haplotypes, Et3, Et13 and Et14, which all represent numerous specimens, were present at all three localities. However, the haplotypes Et13 and Et14 were only represented by a single specimen at T315 and L11, respectively. Only the haplotype Et 2 has previously been collected outside Denmark. The haplotypes Et2, Et12 and Et18 were considerably different from the other Danish haplotypes as shown by the minimum spanning network (Fig. 3).

The inferred phylogeny of the haplotypes was largely unresolved, and the inferred clades had low posterior probabilities except for the clades consisting of haplotype Et2 and Et9 (0.97), and Et13, Et14, Et16 and Et17 (0.91; Fig. 4).

\section{DISCUSSION}

Many new E. testudo haplotypes were found in the present study, increasing the known nucleotide variability of the COI Folmer-fragment from 1.28 to $2.04 \%$. This increase was primarily due to the unique haplotype Et18, which is very different from the other haplotypes (Fig. 3).
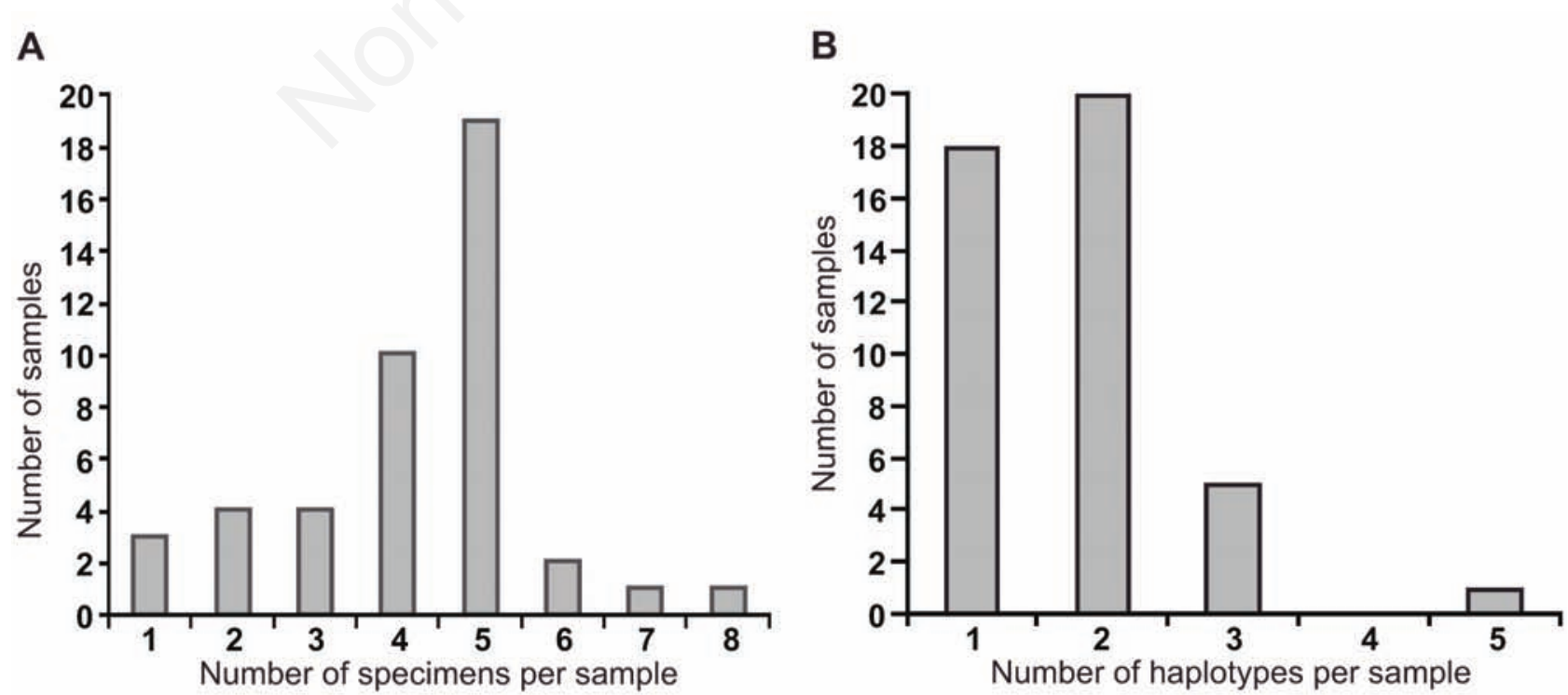

Fig. 2. Histograms of the distribution of cytochrome c oxidase subunit I (COI) haplotypes and specimens in the moss cushions. A) Number of samples (moss cushions) with sequences from 1-8 specimens; B) number of samples (moss cushions) with 1-5 COI haplotypes. 
The maximum pairwise genetic variation was $1.19 \%$ between non-singleton haplotypes - a value similar to that of Jørgensen et al. (2007). Two groups of COI haplotypes from Ramazzottius oberhaeuseri (Doyère, 1840) collected at a site in Italy each showed $0.3-0.6 \%$ variation, which is comparable to many of the samples in the present study (Faurby et al., 2008). Gómez et al. (2000) found a maximum of $3.2 \%$ genetic variation in COI within the planktonic rotifer Brachionus plicatilis Müller, 1786 from a Spanish lake.

Locality T101 only had three haplotypes (Et3, Et13 and Et14) despite having the highest number of sequenced specimens, whereas localities T315 and L11 had six and seven haplotypes, respectively. The higher variability at some localities might reflect chance events related to passive wind dispersal and parthenogenetic reproduction allowing single specimens to reproduce following a, perhaps rare, dispersal event. Passive wind dispersal of tardigrades has been demonstrated by Janiec (1996), and suggested on the basis of molecular data by Jørgensen et al. (2007). Our data suggest that $E$. testudo (probably as cryptobiotic tuns) have dispersed across the Baltic sea, as haplotypes Et3, Et13 and Et14 are present at all three localities. Likewise haplotypes Et2, Et12 and Et18 may have dispersed to the Danish localities from far away as they are more closely related to non-Danish haplotypes (Fig. 3). Dispersal within

Tab. 1. Echiniscus testudo cytochrome c oxidase subunit I haplotypes. Haplotypes Et2, Et3 and Et9 are recollected from the study by Jørgensen et al. (2007). Haplotypes Et12-Et18 represent new haplotypes reported in the present study. Haplotype Et1 from Echiniscus cf. testudo has not been included as we suspect that the Himalayan specimens belong to a distinct species closely related to E. testudo.

\begin{tabular}{|c|c|c|c|c|}
\hline \multirow[t]{2}{*}{ Haplotype } & \multicolumn{4}{|c|}{ Locality } \\
\hline & 2007 study & L11 & T101 & T315 \\
\hline Et2 & France, Germany & 2 specimens & - & - \\
\hline Et3 & L11 2005 & 19 specimens & 25 specimens & 41 specimens \\
\hline Et4 & Israel & & & \\
\hline Et5 & Italy & & & \\
\hline Et6 & Morocco & & & \\
\hline Et7 & Egypt & & & \\
\hline Et8 & Morocco & & & \\
\hline Et9 & L11 2003 & - & 1 specimen & 2 specimens \\
\hline Et10 & T315, Greece, Greenland & & & \\
\hline Et11 & Faroe islands & & & \\
\hline Et12 & - & - & - & 10 specimens \\
\hline Et13 & - & 28 specimens & 18 specimens & 1 specimen \\
\hline Et14 & - & 1 specimen & 28 specimens & 5 specimens \\
\hline Et15 & - & 1 specimen & - & - \\
\hline Et16 & - & 1 specimen & - & - \\
\hline Et17 & - & 1 specimen & - & - \\
\hline Et18 & - & - & - & 1 specimen \\
\hline Total: 10 new haplotypes & & 7 haplotypes & 4 haplotypes & 6 haplotypes \\
\hline (185 specimens) & & (53 specimens) & (72 specimens) & (60 specimens) \\
\hline
\end{tabular}

Tab. 2. Genetic diversity (uncorrected/Kimura 2-parameter) within samples (moss cushions), within localities (roofs), and between localities. Number of samples with the highest internal (within the sample) genetic differences is indicated within parentheses.

\begin{tabular}{|c|c|c|c|}
\hline & \multicolumn{3}{|c|}{ Locality } \\
\hline & L11 & T101 & $\mathrm{T} 315$ \\
\hline Range among samples within a locality & $0-1.02 / 0-1.04 \%(1)$ & $0-0.51 / 0-0.52 \%(5)$ & $0-2.07 / 0-2.08 \%(1)$ \\
\hline Mean among samples within a locality & $0.24 / 0.24 \%$ & $0.24 / 0.24 \%$ & $0.42 / 0.43 \%$ \\
\hline Range between loc. L11 and T101 (186 km) & $0-1.02 / 0-1.04 \%$ & & \\
\hline Mean between loc. L11 and T101 & $0.26 / 0.26 \%$ & & \\
\hline Range between loc. L11 and T315 (186 km) & $0-2.07 / 0-2.08 \%$ & & $0-2.07 / 0-2.08 \%$ \\
\hline Mean between loc. L11 and T315 & $0.40 / 0.40 \%$ & & $0.40 / 0.40 \%$ \\
\hline Range between loc. T101 and T315 (80 m) & & $0-2.25 / 0-2.29 \%$ & \\
\hline Mean between loc. T101 and T315 & & $0.44 / 0.44 \%$ & \\
\hline
\end{tabular}

loc., locality. 
localities might also be mediated by passive wind dispersal; albeit it is also possible that the tardigrades actively disperse on the roof, when it is wet. Another mode of dispersal between closely related samples (moss cushions) could be rain splash dispersal as reported for larvae of the nematode Ostertagia ostertagi (Stiles, 1892). Rain splash dispersal accounted for $90 \%$ of the translocated larvae with most splash-dispersed larvae found within a distance of $90 \mathrm{~cm}$ from the cow pats (Grønvold and Høgh-Schmidt, 1989). Our roof samples were collected in pairs app. $0.5 \mathrm{~m}$ apart. When both samples in a pair contained specimens, more than half of the samples contained the same haplotype (Et3, Et13 or Et14) in both samples. This is an indication of close

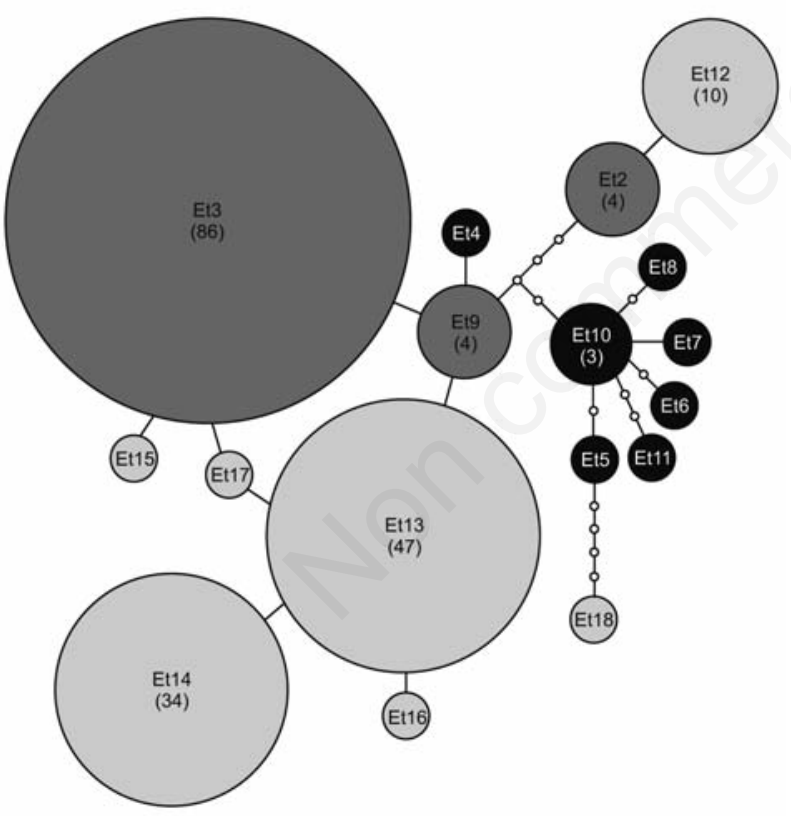

Fig. 3. Minimum spanning network of the cytochrome c oxidase subunit I (COI) haplotypes conducted in TCS. Light grey circles represent the COI haplotypes unique to the present study, dark grey circles represent COI haplotypes found in both the present study and Jørgensen et al. (2007), and black circles represent the COI haplotypes reported only in Jørgensen et al. (2007). The area of the circles is proportional to the frequency of the haplotypes. For all haplotypes with more than one sequence, sequence numbers are found in parentheses below the haplotype name. Each line represents one substitution, and small white circles along a line indicate additional substitutions (hypothetical haplotypes). range dispersal though the dispersal mode is still unknown.

Intensive local sampling did not recollect most of the currently known haplotypes from a previous study on a larger geographical scale (Jørgensen et al., 2007). Actually, recollection in the current study is a rare event, with recollection of only 3 out of 11 previously known haplotypes. The missing recollection of haplotype Et10 is the most noteworthy, as the distribution of Et10 was interpreted as evidence for long range dispersal between Greenland, Denmark and Greece. However, missing or very rare recollections from a single locality are not unusual as haplotype Et9 was not recollected from L11, as in 2007, but was present with one and two specimens at

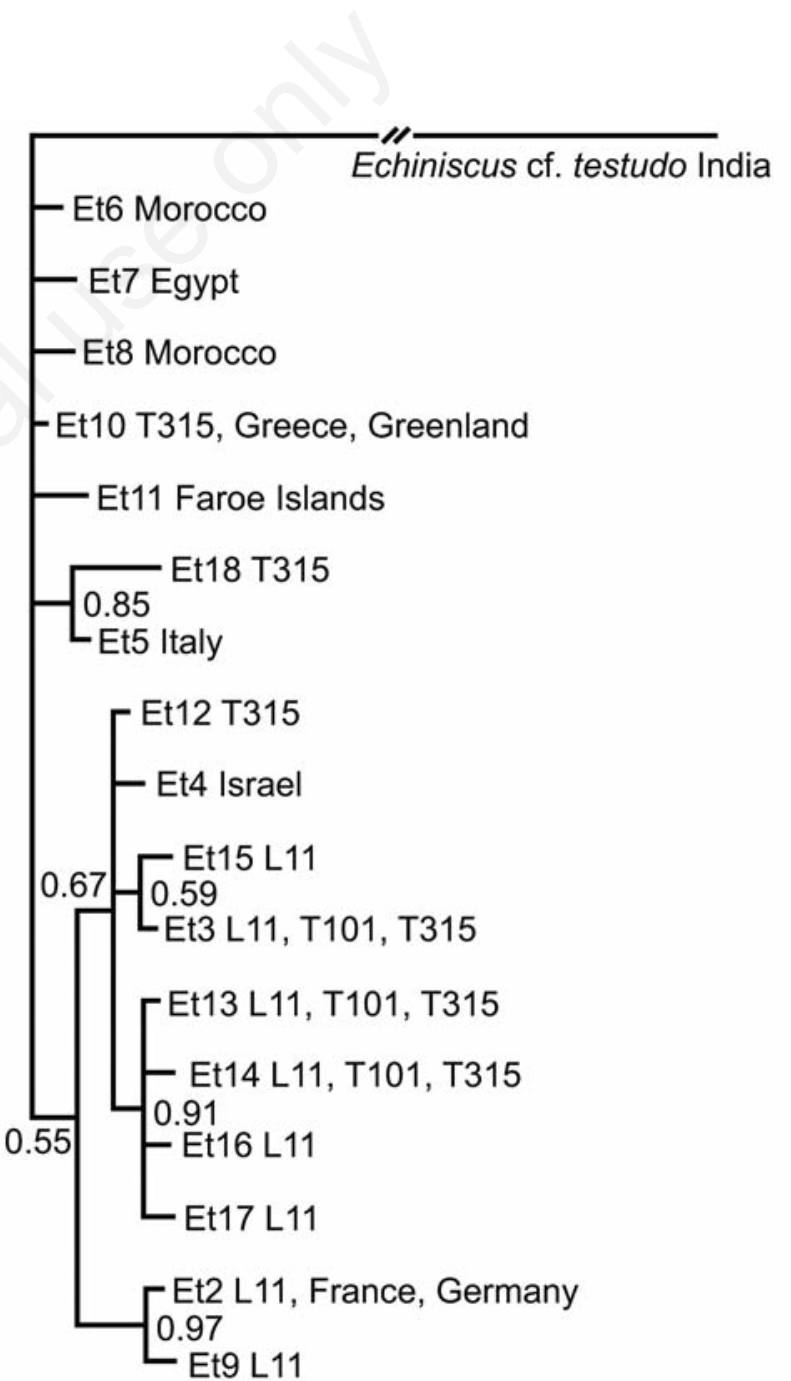

0.1

Fig. 4. Phylogenetic tree inferred by Bayesian inference. Haplotypes both from Jørgensen et al. (2007) and the present study have been included. Haplotypes Et12-Et18 represent new haplotypes. 
T101 and T315, respectively. The pooling of specimens in Jørgensen et al. (2007) represents the possibility of creating artificial chimera sequences constructed from various parts of the multiple COI haplotypes that might be present in the pooled specimens. It should be noted that haplotype Et10 cannot easily be artificially made during sequence assembly by adding two of the known haplotypes together. The artificial construction of Et10 during sequence assembly from the PCR amplification of the forward and reverse primers would require a forward sequence fragment from the very rare haplotype Et9, and a reverse sequence fragment from either of the haplotypes Et5, Et6 or Et7, reported only from Italy, Morocco and Egypt, respectively. Additional samples from Greenland and Crete should be obtained, in order to investigate the elusive haplotype Et10, and to investigate if other tardigrade species show the same dispersal pattern.

Very different haplotypes are present within a single sample (see for example sample 10 at locality T315 with haplotypes Et3, Et12 and Et18; Figs. 1 and 3), stressing the point that pooling of specimens in DNA extractions should be avoided, especially in population genetic studies as recently stated (Sands et al., 2008; Guil and Giribet, 2009). No general pattern of the distribution of haplotypes was evident, as some haplotypes were common at all three localities, whereas other haplotypes were numerous at one locality and scarce at other localities. The occurrence of several unique haplotypes (and four singletons) suggests that we have not yet reached a threshold in the number of haplotypes. Additional sampling would likely increase the number of haplotypes.

\section{CONCLUSIONS}

Future studies on the genetic variation of tardigrade species should focus on a large number of specimens, as some haplotypes have proven to be very rare in the current study. Guil and Giribet (2009) reported 107 haplotypes from 427 specimens in their lineage A in the E. blumicanadensis complex from Sierra de Guadarrama (Spain). Of these, 94 were private, i.e. only occurring at a single sampling site, which further emphasize the need for a huge sampling effort when hunting for new haplotypes.

\section{ACKNOWLEDGMENTS}

The Carlsberg Foundation is thanked for funding the project. Benedikte L. Wilken is thanked for providing laboratory assistance.

\section{REFERENCES}

Clement M, Posada D, Crandall KA, 2000. TCS: a computer program to estimate gene genealogies. Mol. Ecol. 9:16571659.

Dastych H, Kristensen RM, 1995. Echiniscus ehrenbergi sp. n., a new water bear from the Himalayas (Tardigrada). Entomol. Mitt. zool. Mus. Hamburg 11:221-230.

De Gelas K, De Meester L, 2005. Phylogeography of Daphnia magna in Europe. Mol. Ecol. 14:753-764.

Excoffier L, Laval G, Schneider S, 2005. Arlequin ver. 3.0: an integrated software package for population genetics data analysis. Evol. Bioinform. 1:47-50.

Faurby S, Jönsson KI, Rebecchi L, Funch P, 2008. Variation in anhydrobiotic survival of two eutardigrade morphospecies: a story of cryptic species and their dispersal. J. Zool. 275:139-145.

Faurby S, Jørgensen A, Kristensen RM, Funch P, 2011. Phylogeography of North Atlantic tidal tardigrades: refugia, cryptic speciation and the history of the Mid Atlantic islands. J. Biogeogr. 38:1613-1624.

Faurby S, Jørgensen A, Kristensen RM, Funch P, 2012. Distribution and speciation in marine intertidal tardigrades: testing the roles of climatic and geographical isolation. J. Biogeogr. 39:1596-1607.

Folmer O, Black M, Hoeh W, Lutz RA, Vrijenhoek RC, 1994. DNA primers for amplification of mitochondrial cytochrome c oxidase subunit I from diverse metazoan invertebrates. Mol. Mar. Biol. Biotechnol. 3:294-299.

Gómez A, Carvalho GR, Lunt DH, 2000. Phylogeography and regional endemism of a passively dispersing zooplankter: mitochondrial DNA variation in rotifer resting egg banks. Proc. R. Soc. Lond. B 267:2189-2197.

Gómez A, Montero-Pau J, Lunt DH, Serra M, Campillo S, 2007. Persistent genetic signatures of colonization in Brachionus manjavacas rotifers in the Iberian Peninsula. Mol. Ecol. 16:3228-3240.

Gómez A, Serra M, Carvalho GR, Lunt DH, 2002. Speciation in ancient cryptic species complexes: evidence from the molecular phylogeny of Brachionus plicatilis (Rotifera). Evolution 56:1431-1444.

Grønvold J, Høgh-Schmidt K, 1989. Factors influencing rain splash dispersal of infective larvae of Ostertagia ostertagi (Trichostrongylidae) from cow pats to the surroundings. Vet. Parasitol. 31:57-70.

Guidetti R, Bertolani R, 2005. Tardigrade taxonomy: an updated check list of the taxa and a list of characters for their identification. Zootaxa 845:1-46.

Guil N, Giribet G, 2009. Fine scale population structure in the Echiniscus blumi-canadensis series (Heterotardigrada, Tardigrada) in an Iberian mountain range. When morphology fails to explain genetic structure. Mol. Phylogenet. Evol. 51:606-613.

Ishida S, Taylor DJ, 2007. Mature habitats associated with genetic divergence despite strong dispersal ability in an arthropod. BMC Evol. Biol. 7:52.

Janiec K, 1996. Short distance wind transport of microfauna in maritime Antarctic (King George Island, South Shetland Islands). Polar Res. 17:203-211.

Jensen JL, Bohonak AJ, Kelley ST, 2005. Isolation by distance, web service. BMC Genetics 6:13.

Jørgensen A, Møbjerg N, Kristensen RM, 2007. A molecular study of the tardigrade Echiniscus testudo (Echiniscidae) reveals low DNA sequence diversity over a large geographical area. J. Limnol. 66:77-83.

Jørgensen A, Møbjerg N, Kristensen RM, 2011. Phylogeny and 
evolution of the Echiniscidae (Echiniscoidea, Tardigrada): an investigation of the congruence between molecules and morphology. J. Zool. Syst. Evol. Res. 49:6-16.

Kristensen RM, 1987. Generic revision of the Echiniscidae (Heterotardigrada), with a discussion of the origin of the family, p. 261-335. In: R. Bertolani (ed.), Biology of Tardigrades. Selected Symposia and Monographs. U.Z.I., Mucchi ed.

Larkin MA, Blackshields G, Brown NP, Chenna R, McGettigan PA, McWilliam H, Valentin F, Wallace IM, Wilm A, Lopez R, Thompson JD, Gibson TJ, Higgins DG, 2007. Clustal W and Clustal X version 2.0. Bioinformatics 23:2947-2948.

Maniatis T, Fritsch EF, Sambrook J, 1982. Molecular Cloning: A Lab Manual. Cold Spring Harbor Laboratory Publ., New York: $545 \mathrm{pp}$.

McInnes S, 1994. Zoogeographic distribution of terrestrial/freshwater tardigrades from current literature. J. Nat. Hist. 28:257-352.

Miller WR, Claxton SK, Heatwole HF, 1999. Tardigrades of the Australian antarctic territories: males in the genus Echiniscus (Tardigrada: Heterotardigrada). Zool. Anz. 238:303-309.

Mitchell CR, Romano FAI, 2007. Sexual dimorphism, population dynamics and some aspects of life history of Echiniscus mauccii (Tardigrada; Heterotardigrada). J. Limnol. 66:126131.

Møbjerg N, Halberg KA, Jørgensen A, Persson D, Bjørn M, Ramløv H, Kristensen RM, 2011. Survival in extreme envi- ronments: on the current knowledge of adaptations in tardigrades. Acta Physiol. 202:409-420.

Nylander JAA, 2004. MRMODELTEST v2. Program distributed by the author. Evolutionary Biology Centre, Uppsala University ed.

Ronquist F, Huelsenbeck JP, 2003. MrBayes 3: bayesian phylogenetic inference under mixed models. Bioinformatics 19:1572-1574.

Sands CJ, McInnes SJ, Marley NJ, Goodall-Copestake WP, Convey P, Linse K, 2008. Phylum Tardigrada: an "individual" approach. Cladistics 24:1-11.

Schwendinger PJ, Giribet G, 2005. The systematics of the southeast Asian genus Fangensis Rambla (Opiliones: Cyphophthalmi: Stylocellidae). Invertebr. Biol. 19:297-323.

Straughan DJ, Lehman N, 2000. Genetic differentiation among Oregon lake populations of the Daphnia pulex species complex. J. Hered. 91:8-17.

Suatoni E, Vicario S, Rice S, Snell T, Caccone A, 2006. An analysis of species boundaries and biogeographic patterns in a cryptic species complex: the rotifer - Brachionus plicatilis. Mol. Phylogenet. Evol. 41:86-98.

Tamura K, Dudley J, Nei M, Kumar S, 2007. MEGA4: molecular evolutionary genetics analysis (MEGA) software version 4.0. Mol. Biol. Evol. 24:1596-1599.

Wright JC, Westh P, Ramløv H, 1992. Cryptobiosis in Tardigrada. Biol. Rev. 67:1-29. 